\title{
OBTENČ̃̃O DE CARVÃo PROVENIENTE DA CASCA DE TIMBAUVA (Enterolobium contortisiliquum) E SUA APLICAÇÃO NO PROCESSO DE ADSORÇÃO DO AZUL DE METILENO
}

\author{
J. P., LIMA ${ }^{1}$, G., ALVARENGA ${ }^{2}$ G., R., ROSA ${ }^{3}$, T. J., LOPES ${ }^{4}$ \\ ${ }^{1}$ Universidade Federal do Rio Grande, Escola de Química e Alimentos. \\ ${ }^{2,3}$ Universidade Federal do Rio Grande, Programa de Pós-Graduação em Química \\ Tecnológica e Ambiental. \\ ${ }^{4}$ Universidade Federal do Rio Grande, Programa de Pós-Graduação em Engenharia Química. \\ E-mail para contato: tjlopes @ furg.br
}

RESUMO - Muitas indústrias usam corantes sintéticos para colorir seus produtos. A poluição decorrente do descarte de efluentes industriais em corpos d'água ocasiona um grande problema ambiental. $\mathrm{O}$ presente trabalho teve como objetivo principal, desenvolver e estudar a possibilidade de utilizar resíduos da agroindústria, como a casca de timbaúva na adsorção do corante azul de metileno. Foram avaliados através de técnicas de planejamento experimental, os fatores que afetam a obtenção do carvão e a sua utilização em processos de tratamento de efluentes. A variável temperatura não apresentou influência sobre o poder de adsorção, enquanto que o tempo de carbonização da casca contribuiu de forma negativa e significativa no processo de adsorção na faixa de 18 a 24 min. Portanto, estes resultados iniciais, indicam que o carvão da casca de timbaúva se credencia como adsorvente para tratamento de efluentes aquosos que possuam o corante de azul de metileno.

\section{INTRODUÇÃO}

Há algum tempo, as indústrias e a comunidade científica, em geral, têm se preocupado com o tratamento e o descarte correto de efluentes oriundos de processos industriais. $\mathrm{O}$ descarte e o tratamento incorreto dos efluentes poderão ocasionar danos à saúde pública e ao meio ambiente como: toxicidade, reatividade, corrosividade entre outros riscos químicos e biológicos (Dinâmica Ambiental, 2013). Seja em escala de bancada ou industrial, a purificação e o tratamento de efluentes se conduzem por diversas operações unitárias, mas, principalmente, por adsorção que apresenta alta eficiência de remoção de poluentes e pelo seu baixo custo operacional (Robinson et al., 2001). A transferência de massa na adsorção é caracterizada pelo gradiente de concentração entre o sólido (adsorvente) e a solução fluida (adsorbato) sendo um fenômeno de superfície que é caracterizado pela afinidade entre a superfície sólida e algumas substâncias que envolvem a solução fluida, o que permite separálas dos demais componentes do adsorbato (Gomide, 1988a).

A escolha do adsorvente industrial se dá por diversos aspectos técnicos como: seletividade, inércia química, área específica do material, porosidades (Gomide, 1988b) entre outros, mas, principalmente, pelo baixo custo monetário. O carvão mineral ativado é um 
clássico adsorvente industrial, geralmente empregado como adsorvente em processos industriais, tem um preço alto no mercado pelo custo operacional e pelos equipamentos dispostos à sua fabricação.

Os setores industriais de tratamento de efluentes buscam redução de custos e alta performance dos adsorventes utilizados, mas para isso a comunidade científica busca novos adsorventes que tenham altos rendimentos e baixo custo. Assim, fomenta-se à pesquisa para novos adsorventes que sejam oriundos de resíduos agroindustriais e visando suceder o carvão ativado mineral (Ozsoy; Kumbur, 2006). No Brasil, é produzida uma vasta variedade de resíduos e subprodutos agroindustriais como: bagaços, cascas de diversas frutas, farelos e outras diversas especialidades de resíduos agrícolas (Silva; Pires, 2014). Para isso, a aplicação de bioadsorventes tem sido uma alternativa atraente para equilibrar custos e bioacumulação de resíduos agroindustriais e, como consequência, minimizar os impactos ambientais. Contudo, às pesquisas fomentam novas alternativas de adsorventes a partir da biomassa residual agroindustrial (Gonçalves et al., 2007).

O interesse por resíduos agroindustriais que apresentam grande capacidade de adsorção, amplo campo de aplicações e avanços no desenvolvimento de tecnologias limpas e sustentáveis vem se destacando nos últimos anos. Assim, o presente trabalho tem como objetivo principal o estudo preliminar do aproveitamento de um bioadsorvente, carvão de casca de timbaúva (Enterolobium contortisiliquum) na remoção de corante azul de metileno em solução aquosa.

\section{MATERIAL E MÉTODOS}

\subsection{MATÉRIA-PRIMA}

Casca de timbaúva: A matéria-prima para obtenção do carvão foi adquirida no município de Santo Antônio da Patrulha, no Estado do Rio Grande do Sul - Brasil no período de janeiro e fevereiro de 2017. Assim, o fluxograma de obtenção de carvão oriundo da casca de timbaúva é mostrado na Figura 1. Sendo que, todo o estudo foi realizado no laboratório de desenvolvimento e simulação de processos da Escola de Química e Alimentos EQA-FURG.

Figura 1 - Fluxograma de transformação da casca de timbaúva em partículas de diâmetros específicos (2,0 a 2,38 mm).

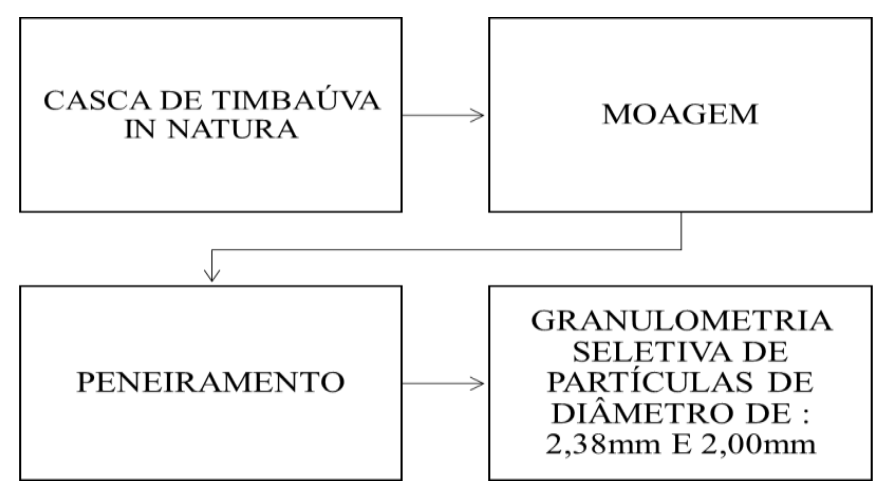


As cascas de Timbaúva, inicialmente, passaram por uma moagem e peneiradas para obtenção de partículas de diâmetro entre 2,00 e 2,38mm.

Corante azul de metileno: O corante utilizado foi o azul de metileno, que é um corante tiazínico, com características catiônicas e com comprimento de onda máximo $(\lambda)$ de $665 \mathrm{~nm}$ (Castro et al., 2009). As determinações da concentração de corante nos experimentos de adsorção foram realizadas através de uma curva padrão com coeficiente de determinação (R2) de 0,9991, Equação 1.

[CONCENTRAÇÃO] $=5,6815 *$ [ABSORBÂNCIA $]$

\subsection{OBTENÇÃO DO CARVÃo E ADSORÇÃo DO AZUL DE METILENO}

O carvão oriundo da casca da semente timbaúva foi obtido através de diversas operações unitárias conforme mostrado no fluxograma, Figura 2.

Figura 2- Fluxograma de obtenção do carvão

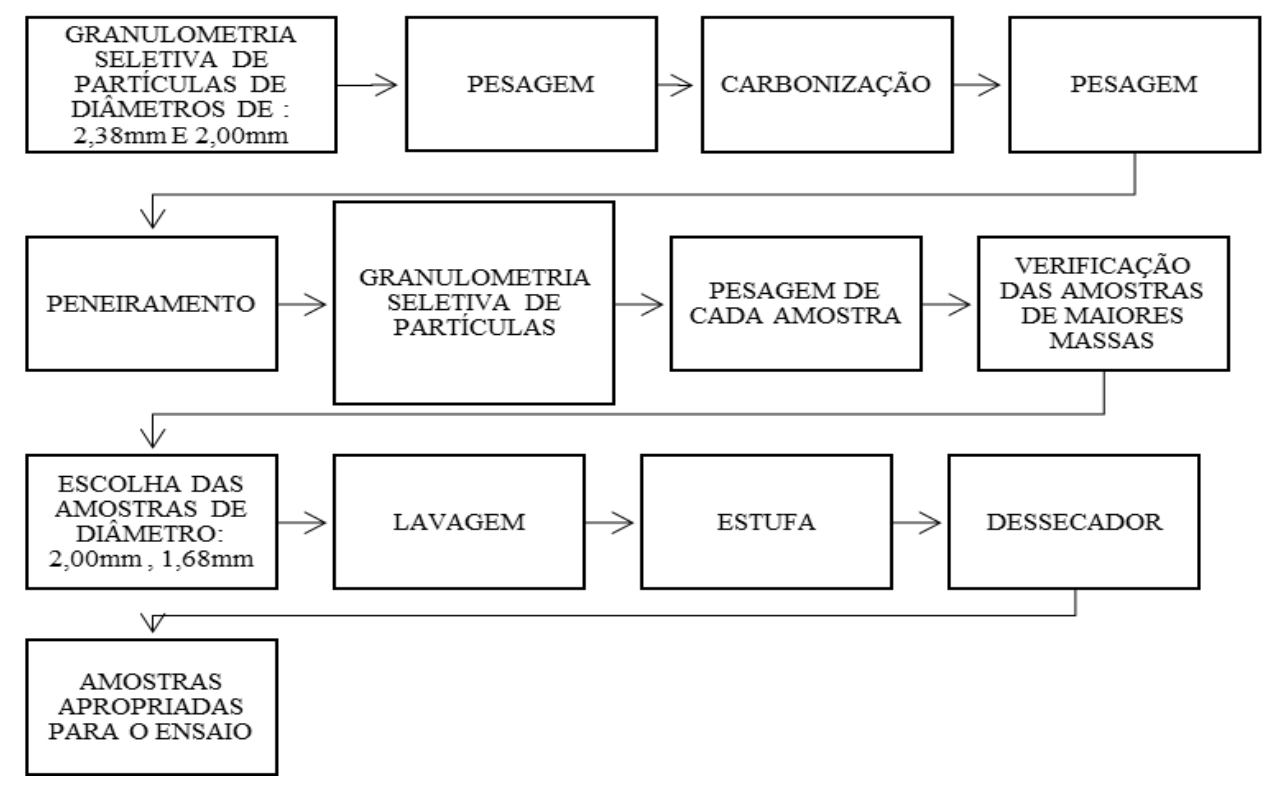

As amostras de cascas de timbaúva trituradas e de diâmetro de 2,00 a 2,38 mm foram submetidas à carbonização em um forno mufla, produzido pela Ind. Com. Fornos Magnu's Ltda., em diferentes condições de tempo e temperatura. As temperaturas utilizadas na carbonização foram de 300 e $500^{\circ} \mathrm{C}$; e tempo de 20 e $40 \mathrm{~min}$, na Tabela 1 . Também, foi adotado um planejamento experimental fatorial completo 22. Posteriormente, à realização do planejamento, aplicou-se a Metodologia das Superfícies de Resposta (MSR) com o objetivo de obter as condições ótimas de operação.

O carvão obtido foi lavado com água destilada para retirada de cinzas produzidas durante a queima, posteriormente, as amostras de carvão foram secas em uma estufa modelo 
Q314 M-242 fabricado por Quimis a $105^{\circ} \mathrm{C}$ por 4 horas e foram armazenadas em recipientes hermeticamente fechados.

Tabela 1 - Fatores e níveis estudados no tratamento térmico das amostras.

\begin{tabular}{|l|c|c|}
\hline \multirow{2}{*}{} & \multicolumn{2}{|c|}{ Níveis codificados } \\
\cline { 2 - 3 } & -1 & +1 \\
\hline Temperatura $\left({ }^{\circ} \mathrm{C}\right)$ & 300 & 500 \\
\hline Tempo (minutos) & 20 & 40 \\
\hline
\end{tabular}

O poder de adsorção do carvão após passar pelo tratamento térmico foi avaliado para cada ensaio, utilizando-se um sistema estático (batelada), utilizando um volume de $50 \mathrm{~mL}$ de solução de corante azul de metileno com concentração inicial de 30 ppm e $1 \mathrm{~g}$ de adsorvente. Os frascos foram introduzidos em uma mesa agitadora orbital Oxilab, modelo OXI - 304, a uma temperatura de $30^{\circ} \mathrm{C}$ e agitação de $100 \mathrm{rpm}$. Após 8 horas de realização do processo de adsorção, foi retirada uma alíquota do sobrenadante para determinação da concentração de corante via espectroscopia visível.

\section{RESULTADOS E DISCUSSÃO}

O planejamento experimental realizado para o processo de obtenção do carvão da casca de timbaúva é apresentado na Tabela 2 , juntamente com a concentração mássica de corante azul de metileno retida no adsorvente (q).

Tabela 2 - Planejamento experimental para o processo de obtenção de carvão de casca de timbaúva e as respectivas respostas para adsorção do corante.

\begin{tabular}{|l|c|c|c|c|c|}
\hline & $\begin{array}{c}\text { Tempo } \\
\text { (minutos) }\end{array}$ & $\begin{array}{c}\text { Temperatura } \\
\left({ }^{\circ} \mathrm{C}\right)\end{array}$ & $\begin{array}{c}\text { Massa } \\
\text { de } \\
\text { carvão } \\
(\mathrm{g})\end{array}$ & $\begin{array}{c}\text { Conc. Mássica de } \\
\text { corante no } \\
\text { adsorvente }(\mathrm{mg} / \mathrm{g})\end{array}$ & $\begin{array}{c}\text { Conc. de corante } \\
\text { no sobrenadante } \\
(\mathrm{mg} / \mathrm{L})\end{array}$ \\
\hline Ensaio-1 & $20(-1)$ & $300(-1)$ & 14,9354 & 1,3226 & 3,5479 \\
\hline Ensaio-2 & $40(+1)$ & $300(-1)$ & 7,9459 & 1,1940 & 6,1182 \\
\hline Ensaio-3 & $20(-1)$ & $500(+1)$ & 9,5646 & 1,3268 & 3,4623 \\
\hline Ensaio-4 & $40(+1)$ & $500(+1)$ & 7,1271 & 1,2094 & 5,8110 \\
\hline
\end{tabular}

Através dos resultados obtidos na Tabela 2 realizou-se uma análise estatística dos efeitos das duas varáveis independentes: temperatura e tempo, sobre a variável resposta concentração mássica de corante no adsorvente. A escolha do modelo com melhor ajuste foi feita a partir da análise de variância (ANOVA) e do coeficiente de determinação $\left(\mathrm{R}^{2}\right)$. $\mathrm{O}$ modelo empírico a ser utilizado é o de efeitos principais e sem interações.

Com o modelo empírico realizou-se a análise dos efeitos em relação à variável resposta, que se pode observada na Tabela 3. 
Tabela 3. Efeitos e índices estatísticos para o modelo empírico com efeitos principais e sem interações $\left(\mathrm{R}^{2}=0,9980\right)$.

\begin{tabular}{|c|c|c|c|c|c|}
\hline & \multirow[t]{2}{*}{ Efeito } & \multirow[t]{2}{*}{ Desvio Padrão } & \multirow[t]{2}{*}{ Valor de $\mathrm{p}$} & \multicolumn{2}{|c|}{ Limites de confiança } \\
\hline & & & & $-95 \%$ & $+95 \%$ \\
\hline Média/Interações & 1,2632 & 0,0028 & 0,0014 & 1,2276 & 1,2987 \\
\hline (A) Tempo & $-0,1230$ & 0,0056 & 0,0289 & $-0,1940$ & $-0,0518$ \\
\hline (B) Temperatura & 0,0098 & 0,0056 & 0,3305 & $-0,0613$ & 0,0809 \\
\hline
\end{tabular}

Analisando-se a Tabela 3, observa-se que os valores dos efeitos para os fatores de processo temperatura e tempo, apresentam sinal algébrico diferente. No que diz respeito à temperatura, quanto maior o seu valor durante o processo de obtenção do carvão da casca de timbaúva, menor será a remoção de corante azul de metileno no processo de adsorção. Em relação ao tempo, o comportamento foi contrário, o carvão com maior tempo de residência no forno tipo mufla apresentou maior performance na remoção do corante em solução. Também, pode-se observar que dentro do intervalo de confiança de $95 \%$ utilizado, o tempo e a média são significativos estatisticamente, apresentando um valor de $\mathrm{p}$ (probabilidade) inferior a 5\%, dentro do nível de significância adotado de $5 \%(\alpha)$.

A partir da regressão foram obtidos os coeficientes do modelo empírico para a concentração de corante no adsorvente, o qual é representado pela Equação 1.

$$
q=1,2632-0,0615 A+0,0049 B
$$

Em que: $\mathrm{q}$ = Concentração mássica de azul de metileno no carvão de timbaúva após o processo de adsorção; $\mathrm{A}=$ Temperatura utilizada durante o tratamento térmico da casca de timbaúva; e B = Tempo de residência da casca de timbaúva na Mufla.

A partir da escolha do melhor modelo foi obtido o gráfico das curvas de nível para a variável resposta concentração de corante no sólido, Figura 1.

Figura 1. Curvas de nível para os fatores codificados de temperatura e tempo em relação à resposta concentração de corante no sólido.

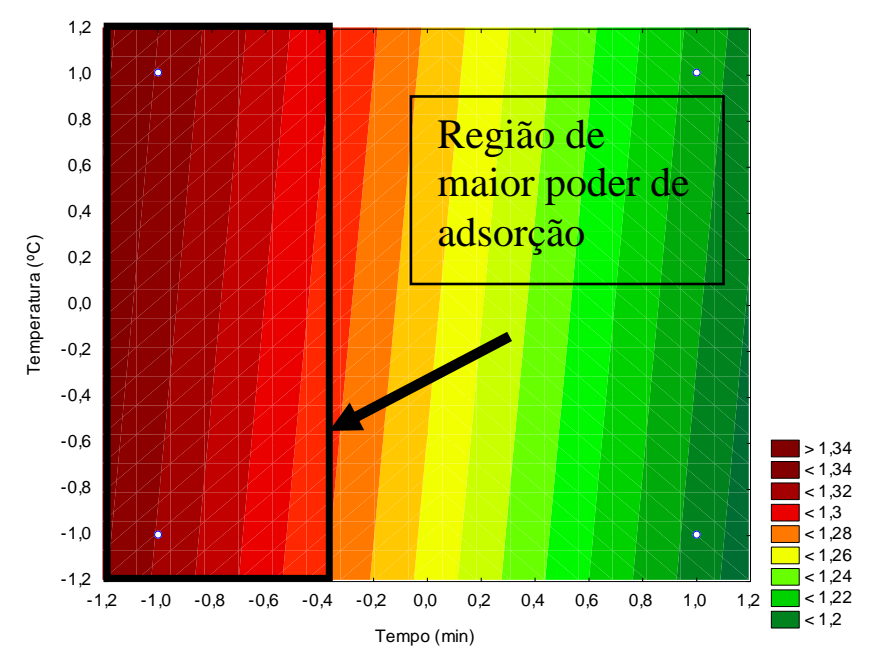


As curvas de níveis (Figura 1) mostram a área em que se estabelece a melhor condição para remoção do corante. A faixa de tempo de tratamento térmico do adsorvente entre 18 a 24 min (níveis -0,6 a -1,2) favoreceu a transferência de corante do líquido para o sólido. Em relação à temperatura pouco afetou o sistema.

\section{CONCLUSÕES}

Através da utilização de técnicas de planejamento experimental, foi possível verificar a influência dos parâmetros tempo e temperatura de tratamento térmico das amostras sobre a capacidade de adsorção do carvão de casca de timbaúva. Assim sendo, observou-se que a variável temperatura não apresentou influencia sobre o poder de adsorção, enquanto que o tempo contribuiu de forma negativa e significativa no processo de adsorção na faixa de 18 a 24 min. Portanto, estes resultados iniciais, indicam que o carvão de casca de timbaúva se credencia como adsorvente para tratamento de efluentes aquosos que possuam o corante de azul de metileno.

\section{REFERÊNCIAS}

CASTRO, C. S.; GUERREIRO,M. C.; OLIVEIRA, L. C. A.; GONÇALVES,M. Remoção de compostos orgânicos em água empregando carvão ativado impregnado com óxido de ferro: ação combinada de adsorção e oxidação em presença de $\mathrm{H}_{2} \mathrm{O}_{2}$. Química Nova, v. 32, n.6, p. 1561-1565, 2009.

DINAMICA AMBIENTAL, A importância do correto descarte de produtos e resíduos químicos. Disponível em: <http://www.dinamicambiental.com.br/blog/reciclagem/a importancia-docorreto-descarte-de-produtos-e-residuos-quimicos/>.Acesso em 19 de fevereiro de 2017.

GOMIDE, R. Operações unitárias: operações de transferência de massa. $1^{\text {a }}$ ed. São Paulo: Dag Gráfica e Editora ltda., 1988 v. 4, p. 311 - 315.

GONÇALVES,M.; GUERREIRO, C. M.; BIANCHI, L. M.; OLIVEIRA, A. C. L.; PEIREIRA, I. E.; DALLAGO, M. R. Produção de carvão a partir de resíduo de ervamate para a remoção de contaminantes orgânicos de meio aquoso, Revista Ciência Agro Técnica, v.31, p. 1386-1391, 2007.

OZSOY, H. D.; KUMBUR, H. Adsorption of $\mathrm{Cu}$ (II) ions on cotton boll. Journal of Hazardous Materials, v.136, p.911-916, 2006.

ROBINSON, T; MCMULLAN, G.; MARCHANT, R.; NIGAM, P. Remediation of dyes in textile effluent: a critical review on current treatment technologies with a proposed alternative. Bioresource Technology, v. 77 p. 247-255, 2001.

SILVA,H,B.;PIRES,J,L. Utilização de carvão adsorvente natural da Amazônia como bioadsorvente para remoção de metais em solução aquosas. Ponto de Partida: Revista Acadêmica Discente do Campus de Marabá, v.3. p. 1-10, 2014. 